\title{
Current Status of Catheter-based Mitral Valve Replacement
}

\author{
Elias Rawish ${ }^{1,2} \cdot$ Tobias Schmidt $^{1,2} \cdot$ Ingo Eitel $^{1,2} \cdot$ Christian Frerker $^{1,2}$
}

Accepted: 14 May 2021 / Published online: 1 July 2021

(C) The Author(s) 2021

\begin{abstract}
Purpose of review Transcatheter mitral valve replacement (TMVR) has been developed to address the need for an alternative therapeutic option to surgery in patients suffering from severe mitral regurgitation who are at high surgical risk. The present review illustrated the state-of-the-art of catheter-based mitral valve replacement evaluating technical characteristics and early clinical experience of different devices to outline prospects and challenges of TMVR.

Recent findings Several devices are currently under clinical assessment. Early experience has demonstrated high procedural success of TMVR. However, TMVR faces several possible hurdles such as left ventricular outflow tract obstruction (LVOTO) after prosthesis deployment, access site complications, and thrombotic risk requiring anticoagulatory therapy.

Summary Future studies should assess long-term prosthesis stability, optimal anticoagulation regime, and occurrence of paravalvular leakage. The development of smaller TMVR prostheses suitable for transseptal implantation could overcome bleeding complications. In perspective, TMVR may emerge to a clinically relevant therapeutic approach for patients with severe MR at high surgical risk.
\end{abstract}

Keywords Transcatheter mitral valve replacement . TMVR - Mitral regurgitation - Transcatheter cardiac therapeutics . Transcatheter mitral intervention · Transcatheter mitral implantation

\section{Introduction}

Mitral regurgitation (MR) is the most common valvular disease in the adult population affecting almost $10 \%$ of individuals over the age of 75 years [1]. Although conventional mitral valve surgery represents the first-line therapy for patients with symptomatic severe MR, up to $50 \%$ of those affected are not referred for surgery due to high risks from age and

This article is part of the Topical Collection on Structural Heart Disease

Christian Frerker

christian.frerker@uksh.de

Elias Rawish

elias.rawish@uksh.de

Tobias Schmidt

tobias.schmidt2@uksh.de

Ingo Eitel

ingo.eitel@uksh.de

1 University Hospital Schleswig-Holstein, Medical Clinic II, University Heart Center Lübeck, Lübeck, Germany

2 DZHK (German Centre for Cardiovascular Research), partner site Hamburg/Kiel/Lübeck, Lübeck, Germany comorbidities [2]. An overall 5-year mortality rate of 50\% was reported in unoperated patients [3], emphasizing the pressing requirement for minimally invasive procedures in treatment of severe MR. Indeed, different transcatheter mitral valve devices have emerged for the treatment of MR in highrisk or inoperable patients. The edge-to-edge leaflet repair system MitraClip (Abbott Laboratories, Abbott Park, IL, USA) constitutes the most frequent applied transcatheter mitral valve repair (TMVr) technique for patients with degenerative mitral regurgitation and functional mitral regurgitation. Even though the COAPT trial yielded a lower mortality and lower hospitalization rate due to heart failure in patients treated with TMVr than best medical therapy alone [4], the MITRA-FR trial showed opposing results [5], which have been attributed to different inclusion criteria, as COAPT enrolled a subset of patients who had more severe MR and less advanced left ventricular (LV) failure [6]. Beyond the decisive importance of patient selection, TMVr systems, however, have further significant limitations, including challenging application due to the presence of advanced valve leaflet damage or excessive ventricular remodeling and subsequent persistence or reoccurrence of MR [7]. Transcatheter mitral valve replacement (TMVR) systems may overcome these limitations, as they may offer a "one valve fits all" concept with 
more predictable reduction of MR, and less technically demanding procedures [8]. Thus, the present review will address the current state-of-the-art of catheter-based mitral valve replacement evaluating technical characteristics and early clinical experience of different TMVR devices in patients with native MV to outline prospects and challenges of TMVR.

\section{Anatomical structure and subsequent prosthesis design challenges}

\section{Prothesis anchoring and sealing}

The anatomy of the mitral valve (MV) is considerably more complex than that of the aortic valve (AV). The AV consists of three leaflets in the tube-shaped ascending aorta, allowing straightforward percutaneous access, thereby severe calcification due to calcified aortic valve disease enables the exclusive use of radial forces to seat transcatheter aortic valve replacement (TAVR) devices. By contrast, the MV apparatus is a dynamic three-dimensional (3D) system, consisting of the D- or saddle-shaped rigid annulus, the anterior MV leaflet which is rounded and occupies one-third of the MV annulus, and the semilunar shaped posterior MV leaflet that occupies two-thirds of the MV annulus circumference [9]. These leaflets are attached to the collagenous chordae tendineae that bulge from the papillary muscles, constituting the subvalvular apparatus. Valve fixation in TMVR cannot solely depend on radial forces similar to in TAVR due to a frequent lack of calcification and a dynamic annular region, thus different anchoring techniques have been proposed [10, 11]. These include the usage of counteracting axial forces by tethers (Tendyne valve, Abbott Laboratories, Abbott Park, IL, USA), grasping of native leaflets by ventricular anchors (Tiara valve; Neovasc, Richmond, BC, Canada), atrial and ventricular flanges that latch the MV annulus and leaflets (CardiAQ, Edwards Lifesciences, Irvine, CA, USA), champagne cork-like effect enabling adequate radial forces for fixation (Intrepid valve; Medtronic, Minneapolis, MN, USA), and formation of a landing zone by implanting an anchor ring (HighLife, HighLife Medical, Paris, France) [11]. The delineated anchoring techniques are intended not only to protect against prothesis dislocation but also to prevent paravalvular leakage following valve implantation.

\section{Delivery approach}

Although a percutaneous transfemoral venous approach with subsequent transseptal access is considered less invasive, and thus is the preferred approach for TMVR, its technical implementation is highly challenging because the delivery system has to handle a nearly right-angle bend within a fairly small space to reach the MV following transseptal puncturing.
Therefore, especially early TMVR systems have been developed to deliver the valve prosthesis transapically. However, higher complication rates and poorer outcomes have been associated with the transapical approach in TAVR compared with transfemoral access $[12,13]$. While transapical patients had a higher base morbidity than transfemoral patients, propensity-matching have revealed an association of transapical approach with increased mortality due to increased bleeding complications and reduced recovery of LV function [13]. Hence, developers are currently focusing on the design of transeptally applicable TMVR prostheses suitable for smaller lumen catheters.

\section{Left ventricular outflow tract obstruction}

Left ventricular outflow tract obstruction (LVOTO) has been reported following surgical implantation of valve prothesis and annuloplasty rings [14] but also after surgical mitral valve repair [15]. LVOTO represents a life-threatening complication with $62 \%$ in-hospital mortality [16], and has been described after transcatheter mitral valve-in-ring procedures as well [17]. Thus, considering the larger prothesis size in TMVR, LVOTO constitutes a decisive design obstacle [18]. TMVR-induced LVOTO has been related to two mechanisms: Fixed obstruction, which follows anterior MV leaflet shifting toward the interventricular septum by the TMVR prosthesis, creating a narrowed and elongated neo-LVOT [19]; and dynamic obstruction, which is predisposed by long anterior MV leaflet and relies on Bernoulli forces rendered by the narrowed neoLVOT that pull the anterior MV leaflet toward the interventricular septum during systole $[20,21]$. The Neo-LVOT area should be predicted by pre-procedural time-resolved computed tomography (CT) to identify patients at increased anatomical risk for LVOTO. For that approach, end-systolic measurements are commonly used [22]. However, Meduri et al. have recently shown that multiphase and particularly early systolic neo-LVOT assessment is superior to end-systolic estimation in determining risk of LVOTO, significantly increasing patient eligibility, as over one-half of patients previously screen-failed were eligible for treatment using early systolic assessment [23]. Thus, further prospective studies should validate this method because it could allow a much broader treatment population. With respect to preventive strategies against LVOTO in high-risk patients, prophylactic alcohol septal ablation has been reported to be effective in some cases [24]. However, it is not anatomically feasible in all patients and can be accompanied by further reduction of LV function, need for permanent pacemaker, and ventricular septal defects [25]. In addition, septal ablation delays TMVR by 4 to 6 weeks. Thus, radiofrequency ablation-based septal correction to prevent iatrogenic LVOTO (SCORPION) procedure has recently been evaluated to increase LVOT diameter prior to TMVR: While three out of three patients underwent successful SCORPION, 
all patients developed high-grade atrioventricular block requiring pacemaker implantation [26]. However, ventricular septal defect did not occur [26].

Another promising approach is the intentional laceration of the anterior MV leaflet to prevent the LVOTO (LAMPOON) procedure, which aims to preserve the anterior MV leaflet from covering the open cells of the TMVR prosthesis [21]. Indeed, a recent clinical trial yielded the feasibility of LAMPOON to prevent LVOTO from TMVR in patients who were otherwise not treatable, with acceptable safety [21]. However, this technically challenging approach is only suitable to TMVR devices with an open-cell design, that is, SAPIEN 3 valve (Edwards Lifesciences, Irvine, CA, USA). Owing to the closed-cell design, laceration of the anterior MV leaflet would not reduce the risk of LVOTO in most novel TMVR devices [23]. While the LAMPOON procedure constitutes a transseptal approach, the balloon assisted translocation of the mitral anterior leaflet to prevent left ventricular outflow obstruction (BATMAN) technique has similar principles to the LAMPOON procedure but only can be performed by using transapical access. Penetrating and ballooning the anterior mitral leaflet results in formation of a hole and posterior translocation of the anterior mitral leaflet to deploy the TMVR valve [27]. However, to date, the BATMAN procedure can only be applied under cardiopulmonary bypass.

\section{Pre- and periprocedural aspects}

\section{Multimodality imaging}

Transthoracic echocardiography (TTE) constitutes the primary imaging modality for the diagnosis and assessment of the mechanism and severity of MR [11]. However, electrocardiogram (ECG)-gated cardiac CT represents the preferred imaging modality for preprocedural TMVR evaluation to confirm patient eligibility based on anatomic characteristics, and predict fluoroscopic angulation as well as access location [28]. The evaluation includes the morphology of the mitral annulus, extent of calcifications in the mitral ring, the subvalvular apparatus, size and shape of left atrium and ventricle, and mitroaortic angle, thereby simulation of the procedure may help to predict possible compilations [7]. Intra-procedural fluoroscopy guides vascular access and catheter manipulation in the cardiac chambers, while (3D) transesophageal echocardiography (TEE) is the primary modality for device deployment, which have been extensively reviewed elsewhere [10]. Recently, echocardiographic-CT scan fusion has emerged as an innovative tool, enabling the visualization of both image modalities in the same visual perspective on the echo screen during TMVR procedure through fusion of pre-interventional CT scan and periprocedural 3D-TEE [29]. Coisne et al. concluded that this technique may be beneficial in catheter crossing of the annular plane avoiding the subvalvular apparatus, position assessment of the delivery system during final deployment, and LVOT impact after deployment of recapturable and retrievable prostheses [29]. Thus, future studies should further evaluate the impact of this technology in clinical practice.

\section{Antithrombotic strategies}

Generally, anticoagulation in the first months after bioprosthesis implantation shall mitigate the risk of thromboembolic events until the valve prosthesis is fully endothelialized [30]. While current ESC and AHA/ACC guidelines recommend the use of oral anticoagulation with a vitamin $\mathrm{K}$ antagonist (VKA) for 3 months and 3 to 6 months, respectively, after surgical bioprosthetic MV replacement [30, 31], there is a lack of recommendations for antithrombotic treatment strategies following TMVR. Importantly, an elevated thrombosis rate $(6 \%$ to $8 \%$ ) was noted at different time points after Tendyne (under antiplatelet therapy) [32•], HighLife (under subtherapeutic anticoagulation) [33], and Fortis (Edwards Lifesciences, Irvine, CA, USA, under VKA plus antiplatelet therapy) device implantation [34], thus the latter one has been withdrawn from clinical use due to the issues with device thrombosis [33]. Indeed, the relatively large size of TMVR prothesis may increase thrombogenicity compared with surgical MV replacement or TAVR. In addition to the design, material and anchoring of TMVR protheses, the interaction between the native and transcatheter valves, patient related factors such as the presence of atrial fibrillation, hypercoagulable status, and left ventricle dysfunction determine thrombogenicity [33]. Considering to date clinical experience, anticoagulation with VKA in the first three months after TMVR procedure seems reasonable in patients who do not have an indication for long-term anticoagulation to diminish the risk of device thrombosis [32•, 33, 35]. An additional antiplatelet therapy could be applied in consideration of the patient's individual bleeding risk as an empirical strategy [33]. Stringent clinical and TTE imaging follow-up is recommended to detect the occurrence of thrombosis. Followup screening with TEE might be beneficial in patients at higher risk of detecting subclinical TMVR thrombosis [36, 37]. However, future studies are needed to distinguish the ideal antithrombotic approach following TMVR, also further underscoring the appropriability of direct oral anticoagulants, as the RIVER trial has recently yielded the non-inferiority of rivaroxaban compared to VKA in patients with atrial fibrillation and a bioprosthetic MV [38]. 


\section{Devices and clinical experiences}

There are numerous devices which have been developed for TMVR. However, most of these are at the early phase of development and have not yet received Food and Drug Administration (FDA) approval or the CE (Conformite Européenne) Mark. Thus, they are applied in studies or for compassionate use. The Tendyne valve is the first one that has received a CE mark approval. Others are expected to follow, whereas clinical use of some TMVR systems has been stopped due to economic or safety reasons, for example, Caisson (LivaNova, London, UK) and Fortis (Edwards Lifesciences, Irvine, CA, USA). Devices in clinical use are summarized in Table 1.

\section{Transapical approaches}

\section{CardiAQ}

The CardiAQ prothesis (Edwards Lifesciences, Irvine, CA, USA) is a non-recapturable, self-expanding, nitinol trileaflet bovine pericardial valve, which was the first dedicated device for TMVR implanted transeptally (catheter size $31 \mathrm{Fr}$ ) in 2012 [39]. The device can be implanted transapically as well, and has two sets of circumferential anchors on the ventricular and atrial side to retain the valve in the mitral annulus. The ventricular anchors are positioned behind the MV leaflets and subvalvular apparatus, maintaining the chords and using native leaflets as support. To minimize LVOTO, the symmetrical valve is supra-annularly positioned. Moreover, the frame is covered by a polyester fabric skirt to reduce the risk for paravalvular leak. First results of the RELIEF (Reduction or Elimination of Mitral Regurgitation in Degenerative or Functional Mitral Regurgitation With the CardiAQ-Edwards Transcatheter Mitral Valve) study (NCT02722551), with 13 patients treated under compassionate use, yielded a technical success of 12/13 (92.3\%) but high all-cause 30-day mortality of $7 / 13(53.8 \%)$ [49]. Edwards Lifesciences has withdrawn the trial and presented a new redesigned device that was renamed the EVOQUE mitral valve replacement system and is described below.

\section{Intrepid}

The Intrepid (Fig. 1) TMVR system (Medtronic, Minneapolis, MN, USA) consists of a symmetrical dual nitinol selfexpanding stent, containing an outer stent frame (fixation frame, available in three sizes: 43,46 , and $50 \mathrm{~mm}$ ) that has a flexible atrial portion, allowing conformability with the native mitral annulus [40]. The stiffer ventricular part is wider than the native annulus, enabling the mentioned "champagne corklike" effect generated by a radial force along the valve stent to

Table 1 Transcatheter mitral valve replacement devices with clinical experiences

\begin{tabular}{|c|c|c|c|c|c|}
\hline Valve name & Manufacturer & Frame & Approach & Anchoring & Size \\
\hline $\begin{array}{l}\text { CardiAQ } \\
\text { [39] }\end{array}$ & $\begin{array}{l}\text { Edwards } \\
\text { Lifesciences }\end{array}$ & $\begin{array}{l}\text { Self-expanding, } \\
\text { nitinol }\end{array}$ & $\begin{array}{l}\text { Transapical, transseptal } \\
\text { (31 Fr) }\end{array}$ & $\begin{array}{l}\text { circumferential anchors on the } \\
\text { ventricular and atrial side }\end{array}$ & $30 \mathrm{~mm}$ \\
\hline Intrepid [40] & Medtronic & $\begin{array}{l}\text { Dual self-expanding } \\
\text { nitinol stent }\end{array}$ & Transapical (35 Fr) & $\begin{array}{l}\text { "champagne cork-like" effect, frictional } \\
\text { elements on outer stent engage leaflets }\end{array}$ & $\begin{array}{l}27 \mathrm{~mm} \text {, (fixation frame, } \\
\text { available in three sizes: } \\
43,46 \text {, and } 50 \mathrm{~mm} \text { ) }\end{array}$ \\
\hline $\begin{array}{l}\text { HighLife } \\
\quad[41]\end{array}$ & $\begin{array}{l}\text { HighLife } \\
\text { Medical }\end{array}$ & $\begin{array}{l}\text { Self-expanding, } \\
\text { nitinol }\end{array}$ & $\begin{array}{l}\text { Transapical }(39 \mathrm{Fr}), \\
\quad \text { (transseptal } \\
\text { implantation of the } \\
\text { ring [18 Fr] })\end{array}$ & "valve in ring" technique & $31 \mathrm{~mm}$ \\
\hline Tiara [42] & Neovasc & $\begin{array}{l}\text { D-shaped } \\
\text { self-expanding, } \\
\text { nitinol }\end{array}$ & $\begin{array}{l}\text { Transapical (32 Fr or } \\
36 \text { Fr) }\end{array}$ & $\begin{array}{l}3 \text { ventricular anchors ( } 2 \text { anterior and } 1 \\
\text { posterior) }\end{array}$ & $35 \mathrm{~mm}$ or $40 \mathrm{~mm}$ \\
\hline $\begin{array}{l}\text { Tendyne } \\
\text { [43] }\end{array}$ & $\begin{array}{l}\text { Abbott } \\
\text { Laboratories }\end{array}$ & $\begin{array}{l}\text { Double frame, } \\
\text { self-expanding, } \\
\text { nitinol }\end{array}$ & Transapical (34 Fr) & Apical tether & $\begin{array}{l}30-43 \mathrm{~mm} \text { anteroposterior } \\
\text { x } 34-50 \mathrm{~mm} \\
\text { commissure-to-- } \\
\text { commissure }\end{array}$ \\
\hline $\begin{array}{l}\text { AltaValve } \\
\quad[44,45]\end{array}$ & $\begin{array}{l}\text { 4C Medical } \\
\text { Technologies }\end{array}$ & $\begin{array}{l}\text { Spherical } \\
\text { self-expanding, } \\
\text { nitinol }\end{array}$ & Transapical (32 F) & $\begin{array}{l}\text { supra-annular position, overexpansion } \\
\text { fit, PET-skirt at the bottom enhances } \\
\text { endothelization and tissue ingrowth }\end{array}$ & $27 \mathrm{~mm}$ \\
\hline $\begin{array}{l}\text { EVOQUE } \\
\quad[46]\end{array}$ & $\begin{array}{l}\text { Edwards } \\
\text { Lifesciences }\end{array}$ & $\begin{array}{l}\text { Self-expanding, } \\
\text { nitinol }\end{array}$ & Transseptal (28 Fr) & $\begin{array}{l}\text { circumferential anchors on the } \\
\text { ventricular and atrial side }\end{array}$ & $44 \mathrm{~mm}$ and $48 \mathrm{~mm}$ \\
\hline $\begin{array}{l}\text { SAPIEN M3 } \\
\quad[47]\end{array}$ & $\begin{array}{l}\text { Edwards } \\
\text { Lifesciences }\end{array}$ & $\begin{array}{l}\text { Balloon-expanding, } \\
\text { nitinol }\end{array}$ & Transseptal (20 Fr) & Nitinol docking system & $29 \mathrm{~mm}$ \\
\hline $\begin{array}{l}\text { Cardiovalve } \\
\quad[48]\end{array}$ & $\begin{array}{l}\text { Cardiovalve } \\
\text { Ltd. }\end{array}$ & $\begin{array}{l}\text { Self-expanding, } \\
\text { nitinol }\end{array}$ & Transseptal (28 Fr) & 24 anchors at ventricular side & 40 to $50 \mathrm{~mm}$ \\
\hline
\end{tabular}




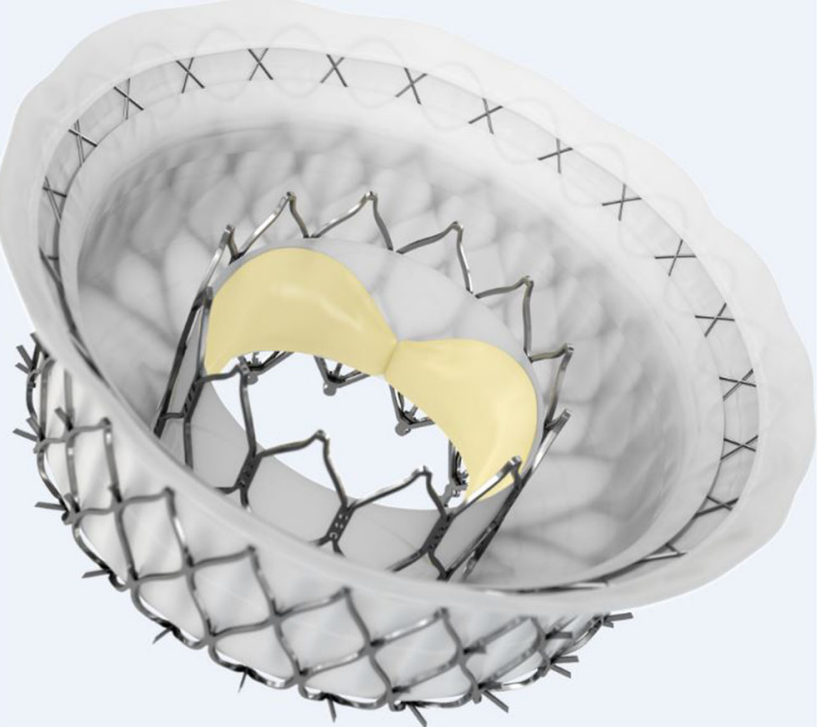

Fig. 1 Intrepid prosthesis (Medtronic Inc.)

diminish the risk of LVOTO. The inner stent frame includes a $27 \mathrm{~mm}$ trileaflet bovine pericardium valve [40, 50]. Circumferential positioned frictional elements on the outer stent further fixate the prosthesis. The native leaflets and chordae are to be preserved and leveraged to seal around the device [51]. To date, the device is implanted via transapical access (35 Fr) under rapid ventricular pacing, and the system has been improved to be recapturable up to the point of final release [18]. The early experience has been published by Bapat et al. in 2018 [52]. Enrolling 50 patients with severe MR and at a very high risk for surgery, the technical success rate was $98 \%$; 30-day mortality rate was $14 \%$, with no disabling strokes [52]. During the follow-up (median 173 days), 11 patients (22\%) died due to a cardiovascular cause [52]. With respect to complications, bleeding was the most common and mostly related to the access site [52]. Furthermore, echocardiography displayed mild or no residual MR in all patients who received the device [52]. The ongoing APOLLO trial (NCT03242642) will evaluate the safety and efficacy of Intrepid TMVR compared to conventional mitral valve surgery in patients with severe MR at high operative risk. Importantly, the FDA approved an early feasibility study for the new transfemoral applicable Intrepid at the end of 2019 , which, considering the mentioned bleeding complications, could improve the safety profile of the Intrepid TMVR system.

\section{HighLife}

The HighLife (Fig. 2) TMVR system (HighLife Medical, Paris, France) is based on a "valve in ring" technique whereby the fixating ring is implanted via the transfemoral approach (18 Fr) in a subannulary position, while the symmetrical

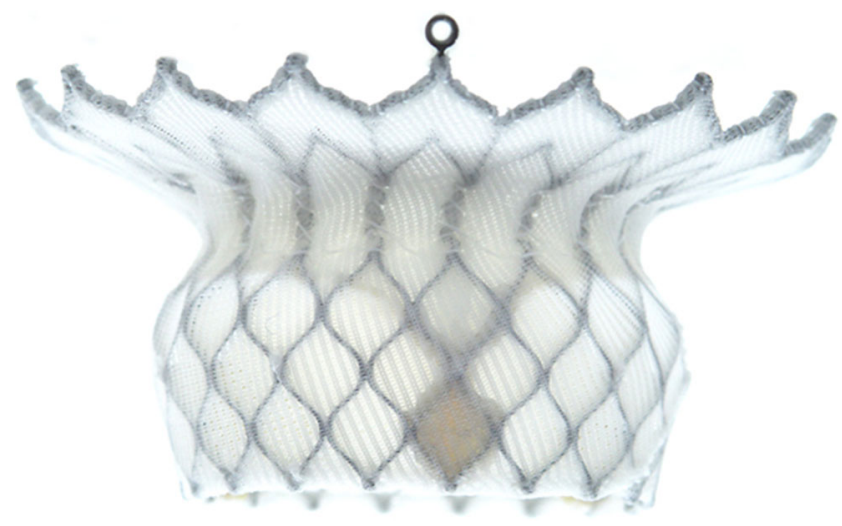

Fig. 2 Highlife prosthesis (Highlife)

polyester covered nitinol trileaflet bovine $31 \mathrm{~mm}$ valve prosthesis is placed inside the ring by transapical access (39 Fr) [41]. Therefore, the native leaflets are caught between the ring implant and the prosthetic valve [53], fixing the anterior mitral leaflet and preserving LVOTO [54]. A systematic review by Del Val et al. yielded a technical success rate of $72.7 \%$ and procedure-related mortality of $18.2 \%$ in a cohort of 15 patients [55••]. One fatal case of LVOTO occurred, while stroke was not reported [55*0]. A feasibility study of a novel transeptally delivered HighLife $28 \mathrm{~mm}$ prosthesis in patients with severe MR at high surgical risk is currently recruiting (NCT04029363).

\section{Tiara}

The Tiara TMVR (Fig. 3) (Neovasc, Richmond, BC, Canada) is a trileaflet bovine pericardial prosthesis with a selfexpanding nitinol frame. The frame is D-shaped, with a ventricular part equipped with three anchors (two anterior and one posterior) and an atrial part with an asymmetric skirt, sealing

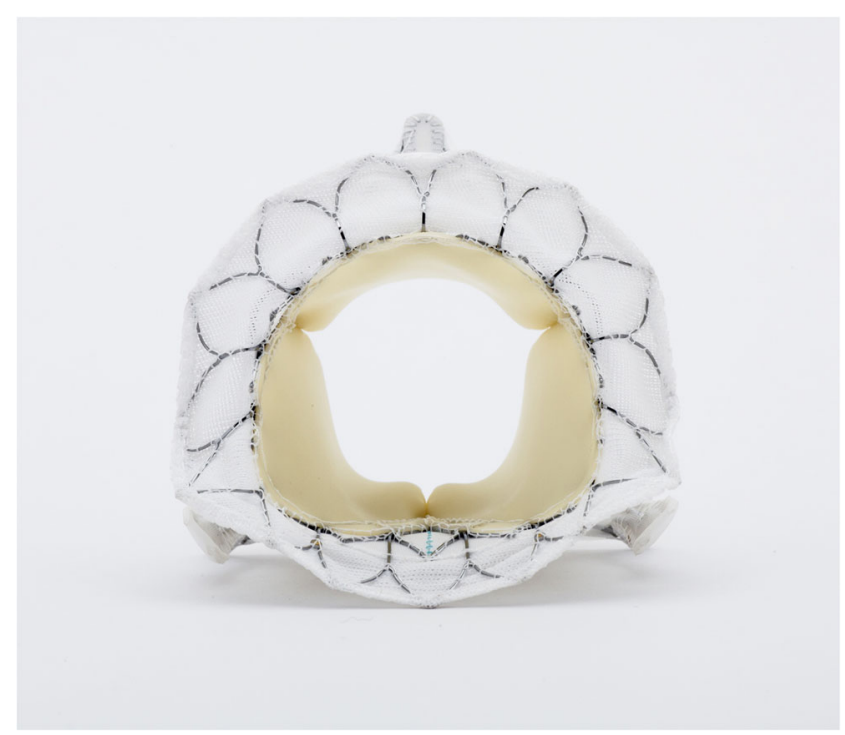

Fig. 3 Tiara prosthesis (Neovasc) 
the prosthesis into the atrial segment of the mitral annulus [42]. The tapered-shaped prosthesis is available in two sizes: $35 \mathrm{~mm}$ and $40 \mathrm{~mm}$. Tiara TMVR is delivered transapically ( 32 Fr or 36 Fr, respectively), whereby careful 3D TEE assessment is crucial to navigate the valve and ensure an optimal alignment of the D-shaped prosthesis in the MV annulus. Repositioning and retrieval can be securely performed prior to the release of the ventricular skirt. The early feasibility trial TIARA I and additional published cases of ongoing TIARA II trial (in total $n=73$ ) displayed a procedural success rate of $93 \%$ and a 30 -day mortality of $11.2 \%$, while $88 \%$ of the patients were free of relevant mitral regurgitation after the procedure [56]. LVOTO has not been reported, while stroke occurred in $5.4 \%$, and access site complication in $6.9 \%$ of the cases [55•*]. Thus, development of a transseptal deliverable Tiara TMVR system would be a substantial benefit to this system.

\section{Tendyne}

The Tendyne (Fig. 4) TMVR system (Abbott Laboratories, Abbott Park, IL, USA) consists of a transapically delivered (34 Fr) trileaflet porcine pericardial valve on a self-expanding nitinol double frame stent and adjustable tether with an apical fixation pad [43]. While the outer stent is available in multiple sizes and D-shaped to adapt to the anatomy of the mitral annulus, the inner stent has a circular shape [18]. The valve is attached to the LV apex by a the epicardially fixed locking pad. An atrial cuff aids to further anchor the valve, avoiding prosthesis entering the ventricle when the tether is tensioned [11]. Remarkably, the Tendyne system is at any time fully retrievable, without need for rapid pacing during deployment [57]. While the first-in-man implantation of the firstgeneration was done in 2013 [58], the second-generation of the Tendyne TMVR system, which features a lower-profile valve to minimize LVOTO, was introduced in 2017 [59]. The initial feasibility study including 100 patients yielded a technical success rate of $96 \%, 30$-day all-cause mortality of $6 \%$, and 1-year all-cause mortality of $26 \%$ [32•]. One instance of major apical bleeding and three cases of stroke were reported [32•]. Furthermore, the Kansas City Cardiomyopathy Questionnaire score was improved by $\geq 10$ points in $73 \%$ of the survivors [32•]. Accordingly, recent computed tomographic angiography analysis displayed a favorable LV remodeling in most patients treated with Tendyne TMVR, as closer proximity of the apical pad to the true apex predicted a favorable remodeling [60]. Thus, the clinical trial to evaluate the safety and efficacy of using the Tendyne MV system for the treatment of symptomatic mitral regurgitation (SUMMIT, NCT03433274) shall compare Tendyne TMVR with the MitraClip system. Because Tendyne TMVR has shown to be feasible in cases of severe mitral annular calcification (MAC) resulting in MR reduction with symptom improvement [61], a MAC cohort has been included in the SUMMIT trial as well.

\section{AltaValve}

The AltaValve TMVR system (4C Medical Technologies, Maple Grove, MN, USA) is composed of a self-expanding spherical-shaped nitinol stent with a $27 \mathrm{~mm}$ trileaflet bovine valve implanted in a supra-annular position, which may particularly diminish probability of LVOTO. A polyethylene terephthalate (PET)-skirt at the bottom of the frame should enhance endothelization and tissue ingrowth to prevent paravalvular leakage. To date, the system is implanted via a transapical approach (32-F), while a transseptal system is currently under development. First-in-human experiences showed the feasibility and procedural success of AltaValve TMVR with positive early clinical and valve hemodynamic outcomes [44, 45]. Thus, the AltaValve early feasibility study (NCT03997305) will further illuminate the safety and performance of the AltaValve for the treatment of moderate to severe or severe MR in patients who are considered high risk for mortality and morbidity from conventional open-heart surgery.

Fig. 4 Tendyne prosthesis (Abbott Vascular) 


\section{Transseptal approaches}

\section{EVOQUE}

The EVOQUE (Fig. 5) (Edwards Lifesciences, Irvine, CA, USA) valve is available in two sizes ( $44 \mathrm{~mm}$ and $48 \mathrm{~mm}$ ) that are compatible with a single delivery system. The low profile $28 \mathrm{Fr}$ transseptal steerable delivery system enhances the maneuverability and depth control during a transfemoraltransseptal approach. A lower ventricular projection further minimizes LVOTO. A first in human experience in 14 patients treated with the EVOQUE mitral valve replacement system showed a technical success rate of $92.9 \%$ and a postimplantation MR reduction to mild or less in $92.9 \%$ of the patients. At 30 days, an all-cause mortality rate of $7.1 \%$ (one non-cardiovascular mortality case due to pneumonia) and two strokes (14.3\%) were reported [46]. Including two patients with paravalvular leak closure, MR was mild or less in all implanted patients at 30 days, with no MR in 10 (83.3\%) [46]. Further clinical studies are required to validate these first encouraging results, and the Edwards EVOQUE TMVR Early Feasibility Study for the treatment of clinically significant symptomatic MR (NCT02718001) is currently recruiting. The EVOQUE valve replacement system is now in trials for use in the tricuspid position.

\section{Sapien M3}

The SAPIEN M3 system (Edwards Lifesciences, Irvine, CA, USA) is based on the SAPIEN 3 TAVI system and consists of a PET-covered nitinol stent with a trileaflet bovine pericardial valve. Furthermore, the SAPIEN M3 TMVR system has a nitinol dock that encircles the chordae tendineae, securing the native MV leaflets and holds the valve in place [47]. The first-in-human study in patients with severe symptomatic MR at high surgical risk $(\mathrm{n}=10)$ showed technical success in $90 \%$, total MR reduction to $\leq$ mild in $88.8 \%$ of implanted patients,

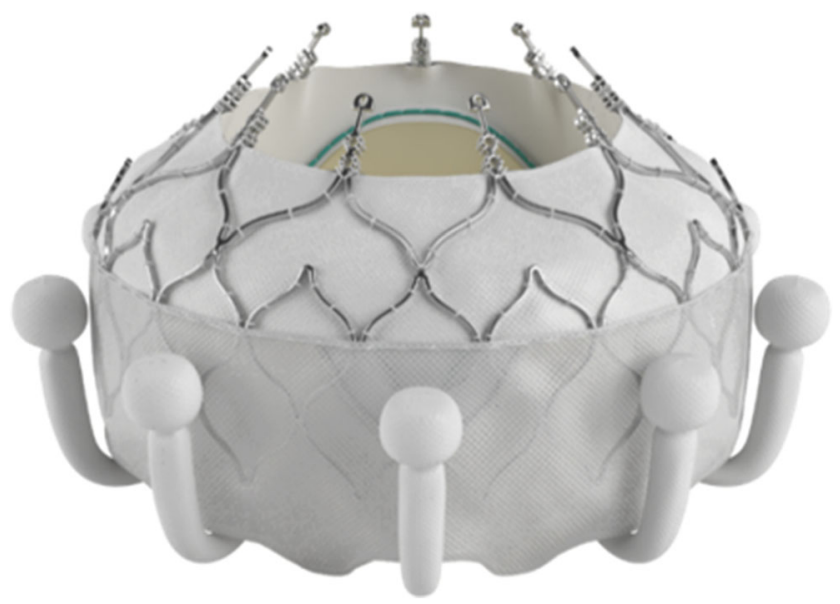

Fig. 5 Evoque prosthesis (Edwards Lifesciences) no cases of death, and no stroke or LVOTO at 30 days [47]. Hence, the ENCIRCLE trial is currently recruiting to further establish the safety and effectiveness of the SAPIEN M3 system in patients with severe MR for whom surgical or TMVr options are deemed unsuitable (NCT04153292).

\section{Cardiovalve}

The Cardiovalve (Fig. 6) TMVR system (Cardiovalve Ltd., Or Yehuda, Israel) is composed of a self-expandable symmetrical trileaflet valve that includes both an atrial frame and a ventricular frame, delivered through a transseptal approach (28 Fr) [48]. The prosthesis is fixed into the mitral annulus by 24 anchors at the ventricular side [11]. It has a height of just $32 \mathrm{~mm}$ resulting in a low ventricular profile with no atrial protruding, thereby minimizing the risk for LVOTO [11]. Cardiovalve is available in three different size variations ranging from 40 to $50 \mathrm{~mm}$ [11]. First results of the ongoing AHEAD (European Feasibility Study of the Cardiovalve Transfemoral Mitral Valve System, NCT03339115) have shown a technical success rate of $100 \%(\mathrm{n}=5)$ with reduction of MR but a high 30-day mortality rate of $60 \%$. A 2-year follow-up of the first human case with the Cardiovalve TMVR system has recently been published, demonstrating good prosthesis function (mean gradient $4 \mathrm{~mm} \mathrm{Hg}$; no paravalvular leak) [48]. Therefore, further study results should be followed closely to evaluate the feasibility and risk profile of Cardiovalve TMVR.

\section{Conclusion}

Untreated symptomatic MR is associated with a poor prognosis. Owing to demographic transition and subsequent increase of (frail) elderly patients, TMVR has emerged as a potential alternative to surgery. Numerous devices are under clinical assessment, and the early experience has shown high procedural success of TMVR. Because the technique faces several possible obstacles such as LVOTO after prosthesis deployment and access site complications, a careful preprocedural evaluation and dedicated patient selection is required. Future studies should address long-term prosthesis stability and degeneration, development of paravalvular leaks, and the risk of device thrombosis to distinguish optimal anticoagulation for each of the TMVR systems. Special attention will be paid to the evolution of TMVR prostheses suitable for less invasive transseptal implantation, as the transapical approach has been associated with poorer outcomes due to access site complications. Overall, TMVR could become a real alternative for patients with severe MR at high surgical risk. 
Fig. 6 Cardiovalve prosthesis (Cardiovalve)

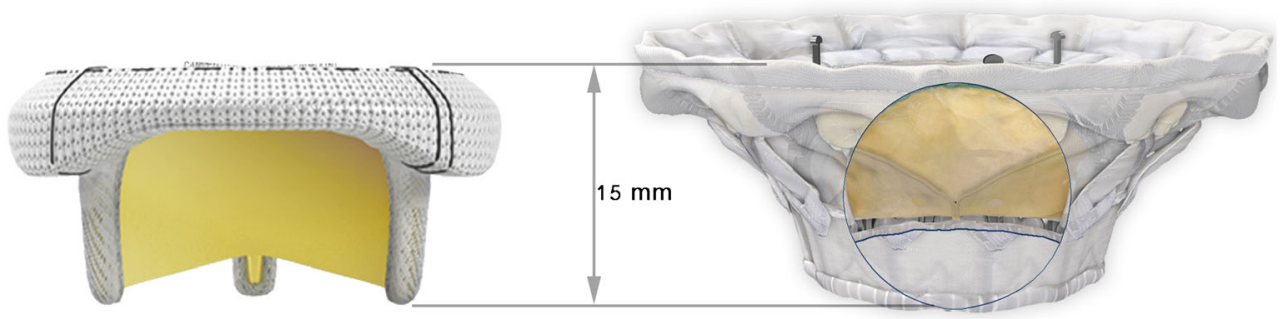

Funding Open Access funding enabled and organized by Projekt DEAL.

\section{Declarations}

Conflict of Interest The authors declare that they have no conflict of interest.

Human and Animal Rights and Informed Consent This article does not contain any studies with human or animal subjects performed by any of the authors.

Open Access This article is licensed under a Creative Commons Attribution 4.0 International License, which permits use, sharing, adaptation, distribution and reproduction in any medium or format, as long as you give appropriate credit to the original author(s) and the source, provide a link to the Creative Commons licence, and indicate if changes were made. The images or other third party material in this article are included in the article's Creative Commons licence, unless indicated otherwise in a credit line to the material. If material is not included in the article's Creative Commons licence and your intended use is not permitted by statutory regulation or exceeds the permitted use, you will need to obtain permission directly from the copyright holder. To view a copy of this licence, visit http://creativecommons.org/licenses/by/4.0/.

\section{References}

Papers of particular interest, published recently, have been highlighted as:

- Of importance

•- Of major importance

1. Nkomo VT, Gardin JM, Skelton TN, Gottdiener JS, Scott CG, Enriquez-Sarano M. Burden of valvular heart diseases: a population-based study. Lancet. 2006;368:1005-11. https://doi. org/10.1016/s0140-6736(06)69208-8.

2. Mirabel M, Iung B, Baron G, Messika-Zeitoun D, Détaint D, Vanoverschelde JL, et al. What are the characteristics of patients with severe, symptomatic, mitral regurgitation who are denied surgery? Eur Heart J. 2007;28:1358-65. https://doi.org/10.1093/ eurheartj/ehm001.

3. Goel SS, Bajaj N, Aggarwal B, Gupta S, Poddar KL, Ige M, et al. Prevalence and outcomes of unoperated patients with severe symptomatic mitral regurgitation and heart failure: comprehensive analysis to determine the potential role of MitraClip for this unmet need. J Am Coll Cardiol. 2014;63:185-6. https://doi.org/10.1016/j.jacc. 2013.08.723.

4. Stone GW, Lindenfeld J, Abraham WT, Kar S, Lim DS, Mishell $\mathrm{JM}$, et al. Transcatheter mitral-valve repair in patients with heart failure. New Engl J Med. 2018;379:2307-18. https://doi.org/10. 1056/NEJMoa1806640.

5. Obadia J-F, Messika-Zeitoun D, Leurent G, Iung B, Bonnet G, Piriou N, et al. Percutaneous repair or medical treatment for secondary mitral regurgitation. New Engl J Med. 2018;379:2297-306. https://doi.org/10.1056/NEJMoa1805374.

6. Pibarot P, Delgado V, Bax JJ. MITRA-FR vs. COAPT: lessons from two trials with diametrically opposed results. Eur Heart J Cardiovasc Imaging. 2019;20:620-4. https://doi.org/10.1093/ ehjci/jez073.

7. Bellini B, Colombo A. Percutaneous mitral valve prostheses: 2019 update. Eur Heart J Suppl. 2020;22:E60-E3. https://doi.org/10. 1093/eurheartj/suaa062.

8. Maisano F, Alfieri O, Banai S, Buchbinder M, Colombo A, Falk V, et al. The future of transcatheter mitral valve interventions: competitive or complementary role of repair vs. replacement? Eur Heart J. 2015;36:1651-9. https://doi.org/10.1093/eurheartj/ehv123.

9. McCarthy KP, Ring L, Rana BS. Anatomy of the mitral valve: understanding the mitral valve complex in mitral regurgitation. Eur J Echocardiogr. 2010;11:i3-9. https://doi.org/10.1093/ ejechocard/jeq153.

10. Blanke P, Naoum C, Webb J, Dvir D, Hahn RT, Grayburn P, et al. Multimodality Imaging in the Context of Transcatheter Mitral Valve Replacement: Establishing Consensus Among Modalities and Disciplines. JACC Cardiovasc Imaging. 2015;8:1191-208. https://doi.org/10.1016/j.jcmg.2015.08.004.

11. Regueiro A, Granada JF, Dagenais F, Rodés-Cabau J. Transcatheter mitral valve replacement: insights from early clinical experience and future challenges. J Am Coll Cardiol. 2017;69:2175-92. https://doi.org/10.1016/j.jacc.2017.02.045.

12. Elmariah S, Fearon WF, Inglessis I, Vlahakes GJ, Lindman BR, Alu MC, et al. Transapical transcatheter aortic valve replacement is associated with increased cardiac mortality in patients with left ventricular dysfunction: insights from the PARTNER I trial. JACC Cardiovasc Interv. 2017;10:2414-22. https://doi.org/10. 1016/j.jcin.2017.09.023.

13. Blackstone EH, Suri RM, Rajeswaran J, Babaliaros V, Douglas PS, Fearon WF, et al. Propensity-matched comparisons of clinical outcomes after transapical or transfemoral transcatheter aortic valve replacement: a placement of aortic transcatheter valves (PARTNER)-I trial substudy. Circulation. 2015;131:1989-2000. https://doi.org/10.1161/circulationaha.114.012525.

14. Guler N, Ozkara C, Akyol A. Left ventricular outflow tract obstruction after bioprosthetic mitral valve replacement with posterior mitral leaflet preservation. Tex Heart Inst J. 2006;33:399-401.

15. Jebara VA, Mihaileanu S, Acar C, Brizard C, Grare P, Latremouille $\mathrm{C}$, et al. Left ventricular outflow tract obstruction after mitral valve repair. Results of the sliding leaflet technique. Circulation. 1993;88: Ii $30-4$.

16. Guerrero M, Urena M, Himbert D, Wang DD, Eleid M, Kodali S, et al. 1-Year outcomes of transcatheter mitral valve replacement in patients with severe mitral annular calcification. J Am Coll Cardiol. 2018;71:1841-53. https://doi.org/10.1016/j.jacc.2018.02.054. 
17. Paradis JM, Del Trigo M, Puri R, Rodés-Cabau J. Transcatheter valve-in-valve and valve-in-ring for treating aortic and mitral surgical prosthetic dysfunction. J Am Coll Cardiol. 2015;66:2019-37. https://doi.org/10.1016/j.jacc.2015.09.015.

18. Goode D, Dhaliwal R, Mohammadi H. Transcatheter mitral valve replacement: state of the art. Cardiovasc Eng Technol. 2020;11: 229-53. https://doi.org/10.1007/s13239-020-00460-4.

19. Blanke P, Naoum C, Dvir D, Bapat V, Ong K, Muller D, et al. Predicting LVOT obstruction in transcatheter mitral valve implantation: concept of the Neo-LVOT. JACC Cardiovasc Imaging. 2017;10:482-5. https://doi.org/10.1016/j.jcmg.2016.01.005.

20. Khan JM, Trivedi U, Gomes A, Lederman RJ, Hildick-Smith D. "Rescue" LAMPOON to treat transcatheter mitral valve replacement-associated left ventricular outflow tract obstruction. JACC Cardiovasc Interv. 2019;12:1283-4. https://doi.org/10. 1016/j.jcin.2018.12.026

21. Khan JM, Babaliaros VC, Greenbaum AB, Foerst JR, Yazdani S, McCabe JM, et al. Anterior leaflet laceration to prevent ventricular outflow tract obstruction during transcatheter mitral valve replacement. J Am Coll Cardiol. 2019;73:2521-34. https://doi.org/10. 1016/j.jacc.2019.02.076.

22. Wang DD, Eng M, Greenbaum A, Myers E, Forbes M, Pantelic M, et al. Predicting LVOT obstruction after TMVR. JACC Cardiovasc Imaging. 2016;9:1349-52. https://doi.org/10.1016/j.jcmg.2016.01. 017.

23. Meduri CU, Reardon MJ, Lim DS, Howard E, Dunnington G, Lee DP, et al. Novel multiphase assessment for predicting left ventricular outflow tract obstruction before transcatheter mitral valve replacement. JACC Cardiovasc Interv. 2019;12:2402-12. https://doi. org/10.1016/j.jcin.2019.06.015.

24. Deharo P, Urena M, Himbert D, Brochet E, Rouleau F, Pinaud F, et al. Bail-out alcohol septal ablation for left ventricular outflow tract obstruction after transcatheter mitral valve replacement. JACC Cardiovasc Interv. 2016;9:e73-e6. https://doi.org/10.1016/ j.jcin.2016.01.010.

25. Guerrero M, Wang DD, O'Neill W. Percutaneous alcohol septal ablation to acutely reduce left ventricular outflow tract obstruction induced by transcatheter mitral valve replacement. Catheter Cardiovasc Interv. 2016;88:E191-e7. https://doi.org/10.1002/ccd. 26649.

26. Lisko J, Kamioka N, Chami ME, Lloyd M, Langberg J, Maidman $\mathrm{S}$, et al. TCT-452 septal correction to prevent iatrogenic left ventricular outflow tract obstruction (SCORPION) prior to transcatheter mitral valve replacement. J Am Coll Cardiol. 2019;74:B447. https://doi.org/10.1016/j.jacc.2019.08.541.

27. Helmy T, Hui DS, Smart S, Lim MJ, Lee R. Balloon assisted translocation of the mitral anterior leaflet to prevent left ventricular outflow obstruction (BATMAN): A novel technique for patients undergoing transcatheter mitral valve replacement. Catheter Cardiovasc Interv. 2020;95:840-8. https://doi.org/10.1002/ccd. 28496.

28. Thériault-Lauzier P, Mylotte D, Dorfmeister M, Spaziano M, Andalib A, Mamane S, et al. Quantitative multi-slice computed tomography assessment of the mitral valvular complex for transcatheter mitral valve interventions part 1: systematic measurement methodology and inter-observer variability. EuroIntervention. 2016;12:e1011-e20. https://doi.org/10.4244/eijy15m11 09.

29. Coisne A, Pontana F, Modine T, Sudre A, Lancellotti P, Hahn RT, et al. Transcatheter mitral valve replacement guided by echocardiographic-ct scan fusion: early human clinical experience. JACC Cardiovasc Interv. 2020;13:1376-8. https://doi.org/10.1016/ j.jcin.2020.02.011.

30. Nishimura RA, Otto CM, Bonow RO, Carabello BA, Erwin JP 3rd, Fleisher LA, et al. AHA/ACC focused update of the 2014 AHA/ ACC guideline for the management of patients with valvular heart disease: a report of the American College of Cardiology/American
Heart Association Task Force on Clinical Practice Guidelines. Circulation. 2017;2017(135):e1159-e95. https://doi.org/10.1161/ cir.0000000000000503.

31. Baumgartner H, Falk V, Bax JJ, De Bonis M, Hamm C, Holm PJ, et al. 2017 ESC/EACTS Guidelines for the management of valvular heart disease. Eur Heart J. 2017;38:2739-91. https://doi.org/10. 1093/eurheartj/ehx391.

32. Sorajja P, Moat N, Badhwar V, Walters D, Paone G, Bethea B, et al. Initial feasibility study of a new transcatheter mitral prosthesis: the first 100 patients. J Am Coll Cardiol. 2019;73:1250-60. https:// doi.org/10.1016/j.jacc.2018.12.066 Largest feasibility study of a TMVR device to date, leading to CE- certification of the Tendyne device.

33. Pagnesi M, Moroni F, Beneduce A, Giannini F, Colombo A, Weisz G, et al. Thrombotic Risk and Antithrombotic Strategies After Transcatheter Mitral Valve Replacement. JACC Cardiovasc Interv. 2019;12:2388-401. https://doi.org/10.1016/j.jcin.2019.07. 055 .

34. Regueiro A, Ye J, Fam N, Bapat VN, Dagenais F, Peterson MD, et al. 2-Year Outcomes After Transcatheter Mitral Valve Replacement. JACC Cardiovasc Interv. 2017;10:1671-8. https:// doi.org/10.1016/j.jcin.2017.05.032.

35. Muller DWM, Farivar RS, Jansz P, Bae R, Walters D, Clarke A, et al. Transcatheter mitral valve replacement for patients with symptomatic mitral regurgitation: a global feasibility trial. J Am Coll Cardiol. 2017;69:381-91. https://doi.org/10.1016/j.jacc.2016.10. 068 .

36. Capretti G, Urena M, Himbert D, Brochet E, Goublaire C, Verdonk $\mathrm{C}$, et al. Valve thrombosis after transcatheter mitral valve replacement. J Am Coll Cardiol. 2016;68:1814-5. https://doi.org/10.1016/ j.jacc.2016.07.757.

37. Urena M, Brochet E, Lecomte M, Kerneis C, Carrasco JL, Ghodbane W, et al. Clinical and haemodynamic outcomes of balloon-expandable transcatheter mitral valve implantation: a 7 year experience. Eur Heart J. 2018;39:2679-89. https://doi.org/ 10.1093/eurheartj/ehy271.

38. Guimarães HP, Lopes RD. de Barros e Silva PGM, Liporace IL, Sampaio RO, Tarasoutchi F, et al. Rivaroxaban in patients with atrial fibrillation and a bioprosthetic mitral valve. N Engl J Med. 2020;383:2117-26. https://doi.org/10.1056/NEJMoa2029603.

39. Søndergaard L, De Backer O, Franzen OW, Holme SJ, Ihlemann N, Vejlstrup NG, et al. First-in-human case of transfemoral cardiaq mitral valve implantation. Circ Cardiovasc Interv. 2015;8: e002135. https://doi.org/10.1161/circinterventions.115.002135.

40. Sorajja P, Bapat V. Early experience with the Intrepid system for transcatheter mitral valve replacement. Ann Cardiothorac Surg. 2018;7:792-8. https://doi.org/10.21037/acs.2018.10.03.

41. Lange R, Piazza N. The HighLife transcatheter mitral valve implantation system. EuroIntervention. 2015;11:W82-3. https://doi.org/ 10.4244/eijv11swa25.

42. Cheung A, Banai S. Transcatheter mitral valve implantation: Tiara. EuroIntervention. 2016;12:Y70-2. https://doi.org/10.4244/ eijv12sya18.

43. Perpetua EM, Reisman M. The Tendyne transcatheter mitral valve implantation system. EuroIntervention. 2015;11:78-9. https://doi. org/10.4244/eijv11swa23.

44. Nunes Ferreira-Neto A, Dagenais F, Bernier M, Dumont E, FreitasFerraz AB, Rodés-Cabau J. Transcatheter mitral valve replacement with a new supra-annular valve: first-in-human experience with the altavalve system. JACC: Cardiovasc Intervent. 2019;12:208-9. https://doi.org/10.1016/j.jcin.2018.10.056.

45. Goel SS, Zuck V, Christy J, Nallamothu N, Jagtap P, Gao J, et al. Transcatheter mitral valve therapy with novel supra-annular altavalve: first experience in the United States. JACC: Case Rep. 2019;1:761-4. https://doi.org/10.1016/j.jaccas.2019.10.034. 
46. Webb J, Hensey M, Fam N, Rodés-Cabau J, Daniels D, Smith R, et al. Transcatheter mitral valve replacement with the transseptal EVOQUE system. JACC Cardiovasc Interv. 2020;13:2418-26. https://doi.org/10.1016/j.jcin.2020.06.040.

47. Webb JG, Murdoch DJ, Boone RH, Moss R, Attinger-Toller A, Blanke $\mathrm{P}$, et al. Percutaneous transcatheter mitral valve replacement: first-in-human experience with a new transseptal system. J Am Coll Cardiol. 2019;73:1239-46. https://doi.org/10.1016/j.jacc. 2018.12.065.

48. Maisano F, Benetis R, Rumbinaite E, Unikas R, Mizariene V, Jakuska $\mathrm{P}$, et al. 2-Year follow-up after transseptal transcatheter mitral valve replacement with the cardiovalve. JACC Cardiovasc Interv. 2020;13:e163-e4. https://doi.org/10.1016/j.jcin.2020.05. 032.

49. Testa L, Popolo Rubbio A, Casenghi M, Pero G, Latib A, Bedogni F. Transcatheter mitral valve replacement in the transcatheter aortic valve replacement era. J Am Heart Assoc. 2019;8:e013352. https:// doi.org/10.1161/JAHA.119.013352.

50. Koh JQ, Walton A, Marasco S, Duffy SJ. Transcatheter mitral valve implantation with the medtronic intrepid ${ }^{\mathrm{TM}}$ transcatheter mitral valve replacement system. Futur Cardiol. 2019;15:281-93. https:// doi.org/10.2217/fca-2018-0082.

51. Meredith I, Bapat V, Morriss J, McLean M, Prendergast B. Intrepid transcatheter mitral valve replacement system: technical and product description. EuroIntervention. 2016;12:Y78-80. https://doi.org/ 10.4244/eijv12sya21.

52. Bapat V, Rajagopal V, Meduri C, Farivar RS, Walton A, Duffy SJ, et al. Early experience with new transcatheter mitral valve replacement. J Am Coll Cardiol. 2018;71:12-21. https://doi.org/10.1016/j. jacc.2017.10.061.

53. Gheorghe L, Brouwer J, Wang DD, Wunderlich N, Rana B, Rensing B, et al. Current devices in mitral valve replacement and their potential complications. Front Cardiovasc Med. 2020;7: 531843. https://doi.org/10.3389/fcvm.2020.531843.

54. Barbanti M, Piazza N, Mangiafico S, Buithieu J, Bleiziffer S, Ronsivalle G, et al. Transcatheter Mitral Valve Implantation
Using the HighLife System. JACC Cardiovasc Interv. 2017;10: 1662-70. https://doi.org/10.1016/j.jcin.2017.06.046.

55.• Del Val D, Ferreira-Neto AN, Wintzer-Wehekind J, Dagenais F, Paradis J-M, Bernier M, et al. Early experience with transcatheter mitral valve replacement: a systematic review. J Am Heart Assoc. 2019;8:e13332. https://doi.org/10.1161/JAHA.119.013332 Most comprehensive and recent systematic review illuminating early experience with TMVR.

56. Conradi L. Innovative design of a transcatheter transapical mitral valve update on TIARA-I and TIARA-II clinical data. Presented at: Euro PCR, Paris. 2019.

57. Quarto C, Davies S, Duncan A, Lindsay A, Lutter G, Lozonschi L, et al. Transcatheter mitral valve implantation: 30-day outcome of first-in-man experience with an apically tethered device. Innovations (Phila). 2016;11:174-8. https://doi.org/10.1097/imi. 0000000000000278.

58. Lutter G, Lozonschi L, Ebner A, Gallo S. Marin y Kall C, Missov E, et al. First-in-human off-pump transcatheter mitral valve replacement. JACC Cardiovasc Interv. 2014;7:1077-8. https://doi.org/10. 1016/j.jcin.2014.06.007.

59. Patel JS, Kapadia SR. The Tendyne transcatheter mitral valve replacement system for the treatment of mitral regurgitation. Futur Cardiol. 2019;15:139-43. https://doi.org/10.2217/fca-2018-0090.

60. Fukui M, Sorajja P, Gössl M, Bae R, Lesser JR, Sun B, et al. Left ventricular remodeling after transcatheter mitral valve replacement with tendyne: new insights from computed tomography. JACC Cardiovasc Interv. 2020;13:2038-48. https://doi.org/10.1016/j. jcin.2020.06.009.

61. Sorajja P, Gössl M, Babaliaros V, Rizik D, Conradi L, Bae R, et al. Novel transcatheter mitral valve prosthesis for patients with severe mitral annular calcification. J Am Coll Cardiol. 2019;74:1431-40. https://doi.org/10.1016/j.jacc.2019.07.069.

Publisher's Note Springer Nature remains neutral with regard to jurisdictional claims in published maps and institutional affiliations. 